\title{
Improved Genetic Algorithm with Two-Level Approximation Method for Laminate Stacking Sequence Optimization by Considering Engineering Requirements
}

\author{
Haichao An, Shenyan Chen, and Hai Huang \\ School of Astronautics, Beihang University, XueYuan Road No. 37, Haidian District, Beijing 100191, China \\ Correspondence should be addressed to Shenyan Chen; chenshenyan@buaa.edu.cn
}

Received 25 September 2014; Accepted 30 December 2014

Academic Editor: Marc Dahan

Copyright (C) 2015 Haichao An et al. This is an open access article distributed under the Creative Commons Attribution License, which permits unrestricted use, distribution, and reproduction in any medium, provided the original work is properly cited.

Laminated composites have been widely applied in aerospace structures; thus optimization of the corresponding stacking sequences is indispensable. Genetic algorithms have been popularly adopted to cope with the design of stacking sequences which is a combinatorial optimization problem with complicated manufacturing constraints, but they often exhibit high computational costs with many structural analyses. A genetic algorithm using a two-level approximation (GATLA) method was proposed previously by the authors to obtain the optimal stacking sequences, which requires significantly low computational costs. By considering practical engineering requirements, this method possesses low applicability in complicated structures with multiple laminates. What is more, it has relatively high dependence on some genetic algorithm control parameters. To address these problems, now we propose an improved GA with two-level approximation (IGATLA) method which includes improved random initial design, adaptive penalty fitness function, adaptive crossover probability, and variable mutation probability, as well as enhanced validity check criterion for multiple laminates. The efficiency and feasibility of these improvements are verified with numerical applications, including typical numerical examples and industrial applications. It is shown that this method is also able to handle large, real world, industrial analysis models with high efficiency.

\section{Introduction}

Due to the advantages of high strength-to-weight and high stiffness-to-weight ratios, laminated composites have been stimulated for wide use in aerospace structures. Optimization design of the corresponding stacking sequences is indispensable to make efficient use of the material properties [15]. For practical laminated structures, however, the basic ply thicknesses are fixed and the available choices of fiber orientation angles are limited to a small set of angles, such as $0^{\circ}, \pm 45^{\circ}$, and $90^{\circ}$. Because of these manufacturing constraints, stacking sequence design then becomes a combinatorial problem of choosing the fiber direction from a permissible set for each ply.

Genetic algorithm (GA) has been preferred extensively to solve this problem $[2-4,6-8]$ which proves to be well suited for the stacking sequence optimization. With their random nature, genetic algorithms (GAs) could produce a variety of alternative designs with similar performance in repeated runs [9], providing the designer with a choice of alternatives. However, one major disadvantage of GAs is that they involve high computational costs in the evaluation of chromosomes. So many studies have concentrated on improving GA's efficiency [3, 9-15]. Among these improvements, approximation concepts with the use of lamination parameters combined with GA have been preferred $[11,13,16]$. With lamination parameters, the problems are simplified and computational costs can be effectively reduced. However, specific programming needs to be developed for structural response analyses and optimal designs are limited to particular laminate configurations [17], consequently restricting their utility in practical engineering applications when lamination parameters are applied.

In a recent study, we have proposed a genetic algorithm using a two-level approximation (GATLA) [18] method for optimizing laminates stacking sequences. Essentially, 
this approach adopts an optimization strategy that the genetic algorithm is integrated within the sequential approximation optimization problems, without using any intermediate variables. This strategy involves only low computational costs and many near optimal solutions could be easily obtained.

For practical engineering stacking sequence optimizations, more than two laminates need to be optimized simultaneously, as practical aerospace structural components usually comprise multiple panels and the stacking sequences of them can remarkably affect structural mechanical properties like strength and stiffness performances $[5,19]$. Even though the GATLA method has been deemed to be able to deal with the optimizations of multiple laminates in simple structures [18], it has not been extended to practical engineering optimizations with multiple laminates. Moreover, the standard GA used in the strategy has relatively high dependence on some genetic parameters, which brings the burden of determining control parameters to the designers or users. Additionally, computational efficiency is another main factor when dealing with optimization problems, especially for large-scale structures. Although the power of the proposed method is undeniable, it seems that there is still space for efficiency improvements.

Thus, in the present study, the main objective is to further improve the performance of this strategy and make it more applicable to address practical engineering problems efficiently. Firstly, the initial design point which was produced randomly was enhanced. Meanwhile, the standard genetic algorithm inside GATLA was modified with a new penalty scheme as well as adaptive crossover probability and variable mutation probability. Moreover, validity check criterion for individual designs when dealing with multiple laminates was also enhanced to further improve the algorithm performance. All of these improvements were firstly verified with numerical examples, and this new strategy was further applied in industrial engineering problems. Significant improvements were obtained with the utilization of these improvements, and the results also showed that this approach could be applied to complicated structures and obtain reasonable stacking sequences with good efficiency.

\section{GATLA Method}

The basic principles of GATLA method will be briefly described in this section. For more details the reader could refer to the literature [18].

2.1. Problem Formulation. To implement the optimization procedure, a ground laminate with arbitrarily given number of plies and permissible orientations, such as $0^{\circ}, \pm 45^{\circ}$, and $90^{\circ}$, is needed before calculation. The corresponding discrete $0 / 1$ variables will decide whether the ply in the ground laminate should be retained or not, and a continuous thickness variable is set for each layer. The concept of ground laminate is similar to the concept of ground structure proposed in truss topology optimization [20]. By determining the existence and absence of truss elements in the ground structure, the optimal layout may be obtained. Back to the present study, some plies might be deleted firstly during the discrete-variable optimization. Furthermore, by increasing the ply thickness after the continuous-variable optimization, several plies might be added. Therefore, by deleting and adding plies to the ground laminate, the optimal stacking sequences could be obtained. The thickness variables seem redundant; however, from lots of calculations, the results of problems considering thickness variables are much better than those without thickness variables, which have been demonstrated in [18]. Based on the ground laminate sequence, the optimization problem can be formulated as follows:

$$
\begin{array}{ll}
\min & f(X) \\
\text { s.t. } & g_{j}(X) \leq 0, \quad j=1, \ldots, m \\
& \alpha_{i} x_{i}^{L}+\left(1-\alpha_{i}\right) x_{i}^{b} \leq x_{i}, \quad i=1, \ldots, n \\
& x_{i} \leq \alpha_{i} x_{i}^{U}+\left(1-\alpha_{i}\right) x_{i}^{b} \\
& \alpha_{i}=0 \quad \text { or } \quad \alpha_{i}=1,
\end{array}
$$

where $X$ is the vector of ply thickness variables, $\alpha$ is the vector of discrete $0 / 1$ variables which represent the existence of each ply, $n$ denotes the total number of plies in the ground laminate, $m$ is the number of constraints, $f(X)$ is the objective function, $g_{j}(X)$ is the $j$ th constraint function, $x_{i}^{U}$ and $x_{i}^{L}$ are the upper and lower bounds on the $i$ th thickness variable $x_{i}$, respectively, and $x_{i}^{b}$ is a very small value (usually $0.01 x_{i}^{L}$ ) used to represent the thickness value of a removed ply. For example, if the ground laminate is given as $\left[(0 / \pm 45 / 90)_{10}\right] \mathrm{s}$, the total number of plies is 80 , and by considering symmetry there are 40 thickness variables $\left(X=\left\{x_{1}, x_{2}, \ldots, x_{40}\right\}^{T}\right)$ and 40 discrete variables $\left(\alpha=\left\{\alpha_{1}, \alpha_{2}, \ldots, \alpha_{40}\right\}^{T}\right)$. It can be seen that the symmetry constraint can be readily achieved by optimizing only one half of the laminate, and the other half would be obtained symmetrically. If the balanced requirement that the number of $+45^{\circ}$ plies should be equal to the number of $-45^{\circ}$ plies is also considered, it can be realized by enforcing the thickness variables of adjacent $+45^{\circ}$ and $-45^{\circ}$ plies in the ground laminate to link together. Moreover, it can be observed that the ply angles in the ground laminate should be selected from the permissible small set of angles. In the end of the optimization, the obtained optimal ply thicknesses need to be rounded to meet the requirement that the ply thickness should be integral multiples to the fixed basic ply thickness. To alleviate matrix cracking problems, it is also required that, in the laminate, there should be no more than four contiguous plies with the same fiber orientation, and it is realized with the use of a penalty term in the objective function, which is to be shown in (8). As for the structural response constraints, $g_{j}(X)$, they are incorporated into the objective function via penalty functions.

2.2. Global Optimization Strategy. The global optimization strategy is introduced based on problem (1). To solve this 
problem, firstly, a first-level approximate problem is constructed using the branched multipoint approximate (BMA) function, which is a piecewise function with two branches for conditions when the corresponding ply exists or is absent, respectively. In the $p$ th stage, the first-level approximate problem can be stated as follows:

$$
\begin{array}{ll}
\min & f^{(p)}(X) \\
\text { s.t. } & g_{j}^{(p)}(X) \leq 0, \quad j=1, \ldots, J_{1} \\
& \alpha_{i} x_{i(p)}^{L}+\left(1-\alpha_{i}\right) x_{i}^{b} \leq x_{i}, \quad i=1, \ldots, n \\
& x_{i} \leq \alpha_{i} x_{i(p)}^{U}+\left(1-\alpha_{i}\right) x_{i}^{b} \\
& \alpha_{i}=0 \text { or } \alpha_{i}=1, \\
& x_{i(p)}^{U}=\min \left\{x_{i}^{U}, \tilde{x}_{i(p)}^{U}\right\}, \\
& x_{i(p)}^{L}=\max \left\{x_{i}^{L}, \tilde{x}_{i(p)}^{L}\right\},
\end{array}
$$

where $\tilde{x}_{i(p)}^{U}$ and $\tilde{x}_{i(p)}^{L}$ are the move limits of $x_{i}$ at the $p$ th stage, $f^{(p)}(X)$ and $g_{j}^{(p)}(X)$ are the approximate functions for objective and constraint functions in the $p$ th stage, respectively, which are created by using the BMA function with the information of the primal functions and their corresponding derivatives at multiple known points, and $J_{1}$ is the number of active constraints of the original problem (1). The BMA functions take the forms as follows:

$$
w^{(p)}(X)=\sum_{t=1}^{H}\left\{w\left(X_{t}\right)+\sum_{i=1}^{n} \widetilde{w}_{i, t}(X)\right\} h_{t}(X)
$$

where

$$
\begin{gathered}
\widetilde{w}_{i, t}(X)= \begin{cases}\frac{1}{r_{o, t}} \frac{\partial w\left(X_{t}\right)}{\partial x_{i}} x_{i t}^{1-r_{o, t}}\left(x_{i}^{r_{o, t}}-x_{i t}^{r_{o, t}}\right) & \text { if } \alpha_{i}=1 \\
\frac{1}{r_{m, t}} \frac{\partial w\left(X_{t}\right)}{\partial x_{i}}\left(1-e^{-r_{m, t}\left(x_{i}-x_{i t}\right)}\right) & \text { if } \alpha_{i}=0,\end{cases} \\
h_{t}(X)=\frac{\bar{h}_{t}(X)}{\sum_{l=1}^{H} \bar{h}_{l}(X)}, \quad t=1, \ldots, H, \\
\bar{h}_{l}(X)=\prod_{\substack{s=1 \\
s \neq l}}^{H}\left(X-X_{s}\right)^{T}\left(X-X_{s}\right),
\end{gathered}
$$

where $w^{(p)}(X)$ represents the objective function $f^{(p)}(X)$ or the constraint function $g_{j}^{(p)}(X), X_{t}$ is the $t$ th known point, and $H$ is the number of points to be counted, bounded previously by $H$ max. The exponents $r_{o, t}$ and $r_{m, t}(t=1, \ldots, H)$ are adaptive parameters used to control the nonlinearity of the approximation, which can be obtained from the following equations:

$$
\begin{aligned}
& \min \sqrt{\sum_{k=1}^{H}\left\{w\left(X_{k}\right)-w\left(X_{t}\right)-\sum_{i=1}^{n} \widetilde{w}_{i, t}\left(X_{t}\right)\right\}^{2}} \\
& \text { s.t. } \quad r_{o}^{L} \leq r_{o, t} \leq r_{o}^{U}, \quad r_{m}^{L} \leq r_{m, t} \leq r_{m}^{U}, \quad t=1, \ldots, H .
\end{aligned}
$$

Since the first-level approximate problem involves both continuous and discrete variables, an optimization strategy is then proposed. Discrete variables (0/1 variables which represent the existence of each ply in the ground laminate) are optimized through GA based on the first-level approximation problem, and when calculating the fitness of the population continuous thickness variables of composite laminate layers are optimized (this procedure is named size optimization hereinafter) by solving the dual problem of the secondlevel approximation, which could significantly reduce the gene code length in the GA and improve the optimization efficiency and accuracy.

The standard GA is used here. During the process of GA, a constrained problem using an exterior penalty function is established firstly as follows:

$$
F_{1}=\phi^{n_{c}}\left[f\left(X^{*}\right)+R \sum_{j=1}^{J_{2}}\left(\max \left\{g_{j}\left(X^{*}\right), 0\right\}\right)^{q}\right]
$$

where $\phi^{n_{c}}$ is treated as a penalty term in the objective function to enforce the requirement that there should be no more than four contiguous plies with the same fiber orientation, which is to alleviate matrix cracking problems; $n_{c}$ is the exponent of the power, and it represents the number of stacks violating the 4-ply contiguity constraint; $\phi=(10 / 9)^{0.5}$ is the penalty parameter for this manufacturing constraint; $R$ is the penalty factor, $q$ denotes the penalty exponent (taken as 1 in this work), and $f\left(X^{*}\right)$ and $g_{j}\left(X^{*}\right)$ are the objective value and constraint values with respect to the optimal thicknesses of given stacking sequences, which are obtained from the process of solving a second-level approximate problem.

By randomly deleting plies form the given ground laminate, an initial population is generated at the beginning of GA [18]. Each individual in the population represents a stacking sequence design, and related ply thickness variables are optimized when the fitness values are calculated. Corresponding to each individual which means a given ply orientation sequence, discrete variables in the first-level approximate problem are fixed and sizing variables of the plies whose corresponding discrete variables are zero will be removed. The deleted plies and related constraints will not exist. The internal sizing (i.e., ply thickness) optimization problem is then established and to address this problem the second-level approximate problem is formed by expanding the objective function and the constraint functions in 


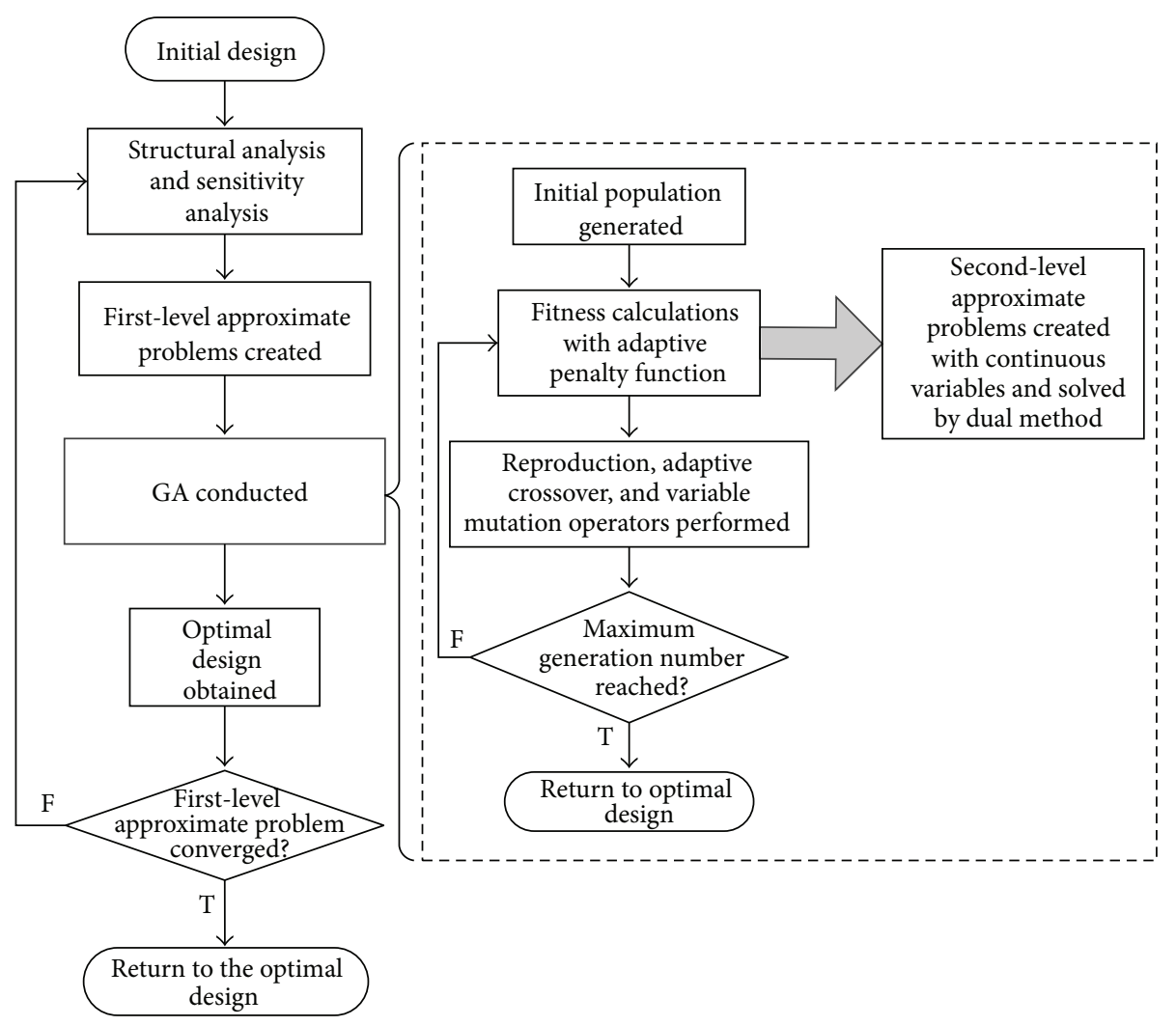

FIGURE 1: Flow chart of global optimization strategy procedure.

the first-level approximate problem into linear Taylor series. In the $k$ th step it is stated as follows:

$$
\begin{aligned}
& \min f^{(k)}(\widetilde{X})=\tilde{f}\left(\widetilde{X}_{(k)}\right)+\sum_{i=1}^{I} \frac{\partial \tilde{f}\left(\widetilde{X}_{(k)}\right)}{\partial \widetilde{x}_{i}}\left(\widetilde{x}_{i}-\widetilde{x}_{i(k)}\right) \\
& \text { s.t. } g_{j}^{(k)}(\widetilde{X})=\widetilde{g}_{j}\left(\widetilde{X}_{(k)}\right) \\
& -\sum_{i=1}^{I} \tilde{x}_{i(k)}^{2} \frac{\partial \widetilde{g}_{j}\left(\widetilde{X}_{(k)}\right)}{\partial \widetilde{x}_{i}}\left(\frac{1}{\tilde{x}_{i}}-\frac{1}{\widetilde{x}_{i(k)}}\right) \leq 0, \\
& j=1, \ldots, J_{2} \text {, } \\
& \bar{x}_{i(k)}^{L} \leq \tilde{x}_{i} \leq \bar{x}_{i(k)}^{U}, \quad i=1, \ldots, I, \\
& \bar{x}_{i(k)}^{U}=\min \left\{x_{i(p)}^{U}, \tilde{x}_{i(k)}^{U}\right\}, \\
& \bar{x}_{i(k)}^{L}=\max \left\{x_{i(p)}^{L}, \tilde{x}_{i(k)}^{L}\right\},
\end{aligned}
$$

where $f^{(k)}(\widetilde{X})$ is the objective function at the $k$ th step, $g_{j}^{(k)}(\widetilde{X})$ is the constraint function, $\widetilde{f}\left(\widetilde{X}_{(k)}\right)$ and $\widetilde{g}_{j}\left(\widetilde{X}_{(k)}\right)$ are obtained from the approximate expressions in (2), $\tilde{x}_{i(k)}^{U}$ and $\tilde{x}_{i(k)}^{L}$ are the move limits at the $k$ th step, and $\bar{x}_{i(k)}^{U}$ and $\bar{x}_{i(k)}^{L}$ are the upper and lower bounds at the $k$ th step.

Dual method is then utilized to deal with the second-level approximate problem. When the second-level approximate problem converges, the fitness of the population could be obtained and genetic algorithm operators are executed to solve the first-level approximate problem. After that, the design variables and the corresponding structural parameters are modified for the next full structural analysis and sensitivity analysis, and then go to the next design cycle.

The flow chart of the strategy is schematically demonstrated in Figure 1. In the end of the optimization procedure, the optimized ply thicknesses are rounded to meet the requirement that they should be integral multiples to the fixed basic ply thickness, and the layers with small value thickness $x_{i}^{b}$ will be removed. The standard GA mentioned previously is replaced with improvement schemes, as shown in Figure 1, which will be described in the next section.

\section{Improvements to GATLA Method}

3.1. Improved Random Initial Design. As stated in Section 2, the optimization process starts from the arbitrarily given ground laminate, with limited orientations and excessive plies. To produce an initial design based on the ground laminate, in the original GATLA method, each ply in the ground laminate is randomly deleted with a relatively high level of probability, for example, 0.9 or larger. Here, this probability is defined as the deleted-ply percentage for the initial design, designated DPID. However, this random operation will probably produce a design with zero plies kept, or in a slightly better condition, with one or two plies retained in the 
ground laminate. Even if the probability to delete each ply is given a smaller value, the case that zero or very few plies are kept is possible to happen.

In order to avoid the producing of the initial design with few plies, here, this random design process is improved. Firstly, the deleted-ply percentage for the initial design, that is, DPID, is multiplied by the total number of plies in the ground laminate, and the obtained product value is rounded to nearest integer. Next, each ply in the ground laminate is randomly deleted as before with the given probability. The number of removed plies is counted, and this amount is then compared with the obtained product value. If the amount of deleted plies is less than the rounded product value, this random produced design is identified as an appropriate initial design. Otherwise, if the number of deleted plies is larger, which means too many plies have been deleted from the ground laminate or even no ply is retained, this produced design then adds plies one by one until the amount of deleted plies is fewer than the rounded product value to be identified as an appropriate initial design. For example, when the ground laminate is $\left[(0 / \pm 45 / 90)_{10}\right] \mathrm{s}$ and DPID is given as 0.9 , the number of removed plies from the ground laminate should not be more than 72 , that is, $80 \times 0.9$. If the generated initial design is $[0 / \pm 45 / 0 / 90 / \pm 45]$ s, the number of kept plies is 14 , and that of the removed plies is 66 . So this design could be identified as an appropriate initial design to go to the next optimization step. However, if the random produced design is $[0 / \pm 45] \mathrm{s}$, the amount of deleted plies is then 74 , which is larger than 72 . Then add plies to this design to generate an appropriate one that meets the requirement. For instance, $[0 / \pm 45 / 0]$ s gets valid after adding 0 -degree layer to the original design.

3.2. New Penalty Scheme in Objective Function. Optimization problems with constraints must be transformed into unconstrained ones as GA is an unconstrained optimization method. In the original GATLA, an exterior penalty function is used to achieve this. As is formulated in (8), penalty control parameters $R$ and $q$ are predefined constants and need to be adjusted according to different optimization problems. The appropriate selection of these parameters plays a crucial role in determining the computational efficiency.

Though various specific penalty schemes have been proposed (see the introduction in [21]), Barbosa and Lemonge developed an adaptive penalty function without any type of user defined penalty parameter. The objective function proposed with an adaptive penalty is written as

$$
F\left(X^{*}\right)= \begin{cases}f\left(X^{*}\right) & \text { if } X^{*} \text { is feasible, } \\ \bar{f}(X)+\sum_{j=1}^{m} k_{j} g_{j}\left(X^{*}\right) & \text { otherwise }\end{cases}
$$

where

$$
\begin{gathered}
\bar{f}(X)= \begin{cases}f\left(X^{*}\right) & \text { if } f\left(X^{*}\right)>\langle f(X)\rangle, \\
\langle f(X)\rangle & \text { otherwise, }\end{cases} \\
k_{j}=\langle f(X)\rangle \frac{\bar{g}_{j}}{\sum_{l=1}^{m}\left[\bar{g}_{l}\right]^{2}},
\end{gathered}
$$

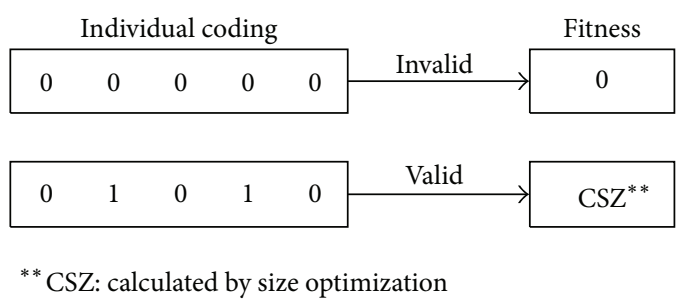

FIGURE 2: One example to illustrate original criterion.

and $\langle f(X)\rangle$ represents the average value of the objective function $f(X)$ over current population, $g_{j}\left(X^{*}\right)$ is the violation of the $j$ th constraint of the individual design corresponding to $X^{*}, \bar{g}_{j}$ is the violation of the $j$ th constraint averaged over the current population, and $m$ is the number of total constraints.

The main feature of this penalty scheme, besides being adaptive and not requiring any predefined parameter, is to automatically define a different penalty coefficient which varies along the run according to the feedback received from the evolutionary process for each constraint. The adaptive scheme also relieves the user from the burden of having to determine, by trial and error, sensitive parameters to cope with every new constrained optimization problem.

Based on this approach, an alternative penalty function was proposed in [22], which also has the same features as (10). Herein, we utilize the consistent type of this formulation [22] but replace the corresponding exponent (i.e., 3) with Figure 2 based on our numerical studies, as established in (12). Furthermore, the optimal design could be considered as the one with the largest possible constraint margin of all individuals of the same objective function [3]. Therefore, a small fraction of the critical constraint value is subtracted from the objective function when all constraints are satisfied. In the present work, the ultimately new form of the unconstrained objective function with adaptive penalty scheme is defined as follows:

$$
F_{1}=\left\{\begin{array}{r}
\phi^{n_{c}}\left[f\left(X^{*}\right)+\langle f(X)\rangle\right. \\
\left.\cdot \varepsilon \max \left\{g_{1}\left(X^{*}\right), \ldots, g_{J_{2}}\left(X^{*}\right)\right\}\right] \\
\text { if } X^{*} \text { is feasible, } \\
\{\bar{f}(X)+\langle f(X)\rangle \\
\left.\cdot\left[\left(1+\sum_{j=1}^{J_{2}} \beta_{j} g_{j}\left(X^{*}\right)\right)^{2}-1\right]\right\}
\end{array}\right.
$$

where

$$
\beta_{j}=\frac{\bar{g}_{j}}{\sum_{l=1}^{J_{2}} \bar{g}_{l}},
$$


and $\beta_{j}$ is the violation percent of the $j$ th constraint in the current population. $\phi=(10 / 9)^{0.5}$ is retained to enforce the 4-ply contiguity constraint and $n_{c}$ is the total number of sameorientations plies in excess of the four contiguously sameorientation plies. $\varepsilon=0.001$ is employed here and we add $\langle f(X)\rangle$ to guarantee the small fraction $\varepsilon$ is neither too small nor too large with respect to the object function value, which makes the function more adaptive. $g_{j}\left(X^{*}\right) \leq 0$ when the $j$ th constraint is satisfied and $g_{j}\left(X^{*}\right)>0$ otherwise. The new objective function established here could automatically adjust the penalty to the infeasible designs from generation to generation and enhance the search capability to obtain a global optimum or get close to it. This adaptive penalty function enables two control parameters, $R$ and $q$ in (8), not to be given any more.

\subsection{Adaptive Crossover and Variable Mutation Probabilities.} In GA, crossover is used to produce new generation by combining a portion of each parent's genetic string and mutation is adopted to add or delete genes by introducing small changes in children created by crossover. The efficiency of GA is often sensitive to the probabilities of crossover and mutation (hereafter referred to as $P_{c}$ and $P_{m}$, resp.) [4], and the choice of both of them critically affects the performance as they are fixed constants in the standard GA. In practice, it is ideal to vary $P_{c}$ and $P_{m}$ adaptively by GA itself. Srinivas and Patnaik [23] proposed a method with adaptive probabilities of crossover and mutation to realize the twin goals of maintaining diversity in the population and sustaining the convergence capacity of GA. Moreover, an improved version of adaptive crossover and mutation operators was proposed by Ren and San [24]. The modified expression for $P_{c}$ is as follows and is utilized in this paper:

$$
P_{c}= \begin{cases}P_{c 1}-\frac{\left(P_{c 1}-P_{c 2}\right)\left(f^{\prime}-f_{\text {ave }}\right)}{f_{\text {max }}-f_{\text {ave }}} & f^{\prime} \geq f_{\text {ave }} \\ P_{c 1} & f^{\prime}<f_{\text {ave }}\end{cases}
$$

where $f_{\max }$ is the maximum fitness value in the population, $f_{\text {ave }}$ is the average fitness value in every population, and $f^{\prime}$ is the larger of the fitness values of the solutions to be crossed. In addition, we set $P_{c 1}=0.9$ and $P_{c 2}=0.6$ for each optimization problem. The modified formulation increases $P_{c}$ of the individuals with the highest fitness value up to $P_{c 2}$, making the best individual no longer in a stagnant state.

The modified expression for $P_{m}$ proposed by Ren and San [24] is similar to that in (14), where $f^{\prime}$ is replaced by $f$, which is the fitness of an individual. Thus, it means the calculation increases by obtaining the fitness of the current population generated after the crossover operator. Actually, it was observed that the use of relatively high mutation rates at the start of the GA-runs could be an efficient aim at preventing premature convergence [25]. Thereafter, a very simple formulation to reduce the probability of mutation in geometric progression proposed by Leite and Topping [25] is adopted in this paper. By giving the initial probability of mutation $P_{m i}$ and the final probability of mutation $P_{m f}$, the coefficient for the reduction of the mutation rate at each generation is determined by

$$
r_{m}=\sqrt[\operatorname{MaxG} G]{\frac{P_{m f}}{P_{m i}}}
$$

where $\operatorname{Max} G$ is the maximum number of generations. In this study, we set $P_{m i}=0.1$ and $P_{m f}=0.001$ for each optimization problem. Thus, $P_{c}$ and $P_{m}$ do not need to be predefined anymore.

\subsection{Enhanced Validity Check Criterion for Multiple Laminates.}

As is stated in Section 2, the optimization procedure is conducted by adding or deleting plies in the given ground laminate. In the process of GA, with the randomness of the initial population and GA operators, there may be some infeasible designs with invalid coding due to the excess removal of plies. Some individuals of these designs may be able to meet all the constraints after size optimization, that is, solving the second-level approximate problems. However, for designs with seriously overmuch removal of plies, even after the size optimization, they may remain serious constraint violations, consequently affecting the convergence to some extent. So there is no more need to perform the secondlevel approximation to these individuals and their fitness values could be directly set to be zero, which could improve the algorithm efficiency as a result. With regard to this, in GATLA, a validity check criterion was put forward for each individual coding. The criterion is that, for each encoded design, when the value of deleted plies is less than a certain percentage relative to corresponding ground laminate, this individual coding can be considered as valid and size optimization afterwards is conducted to achieve the fitness calculation; otherwise, this coding is identified to be invalid and zero is diametrically given to its fitness value without further size optimization. The ratio for this earlier stated judgment is defined as the maximum percentage permissible to delete layers, designated as FITP in [18] and this paper. This parameter should be initially given on the basis of ground laminate layers to guarantee the optimal design included. To illustrate this judgmental procedure, an example is shown in Figure 2. The number of plies in a ground laminate is 5, FITP $=0.8$, and the coding is considered valid when the deleted plies are fewer than 4 (i.e., $5 \times 0.8$ ).

However, deficiency could occur during the implementation of multiple laminates optimization. For example, if there are two laminates as design domain, one of them may be encoded with [000000] among the population, and the other's coding could be [111010]. Apparently there are 12 plies in the ground laminate, and 8 plies are deleted for this individual. If FITP was given to be 0.8 , this coding is identified to be valid according to the original criterion mentioned previously, for 8 is less than 9.6 (i.e., $12 \times 0.8$ ). But no plies are reserved in the first laminate, and obviously this design should be considered invalid. With another three designs, this condition is shown in Figure 3.

Here, in order to overcome this shortcoming, the validity check criterion especially for multiple laminates is enhanced. 


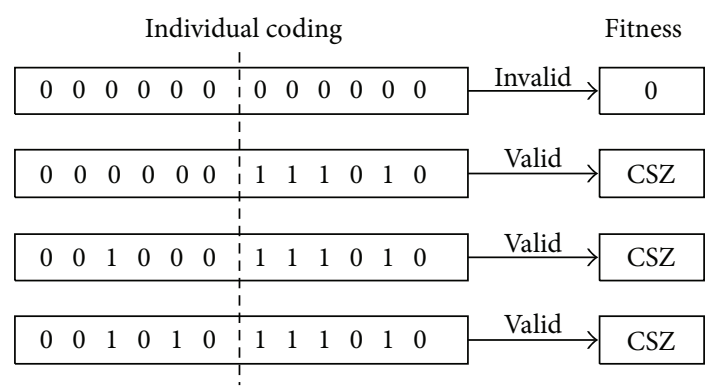

FIGURE 3: Coding judgment using original criterion.

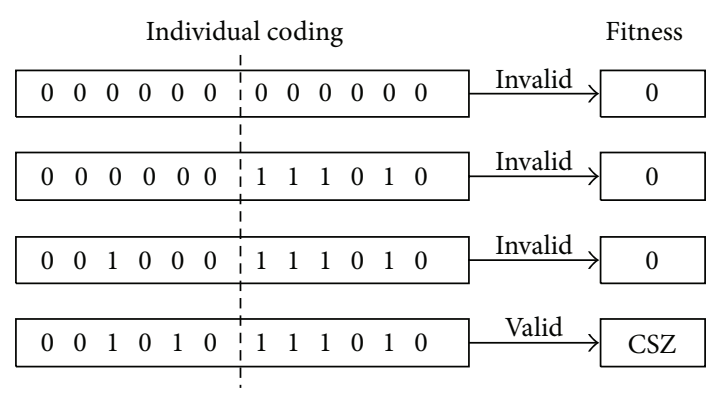

FIGURE 4: Coding judgment using enhanced criterion.

First of all, the original criterion (OC) is implemented to the laminates one by one. When the coding design for each laminate is determined as valid, this individual could possess final validity identification. For the design with two laminates previously mentioned, according to the enhanced criterion (EC), less than 4.8 (i.e., $6 \times 0.8$ ) plies should be removed in each laminate to be judged as valid. See Figure 4 to describe this scheme. It can be easily seen that both original and enhanced criteria are identical for dealing with just one laminate design. These validity checks essentially mean rejecting some designs out of the second-level optimization to improve the algorithm performance.

\section{Numerical Examples}

Numerical examples are conducted in this section to test the improvements by comparing with the original GATLA method. As the GA is a stochastic process, the algorithm performance will be evaluated in terms of reliability and normalized computation price. In this study, the indicator of the normalized price is the average number of evaluations of the structural analysis divided by the reliability of reaching a practical optimum after 200 independent runs here, while the reliability is defined as the fraction of runs that produced a practical optimum during the 200 repeated runs.

4.1. A Composite Cone-Cylinder Structure. The first example deals with the optimization of symmetric stacking sequences of a composite cone-cylinder structure, as shown in Figure 5, which consists of two composite parts: a conic part and a cylindrical part. The dimensions are $r=60 \mathrm{~mm}, R=$ $100 \mathrm{~mm}, a=100 \mathrm{~mm}$, and $b=200 \mathrm{~mm}$. The two ends of

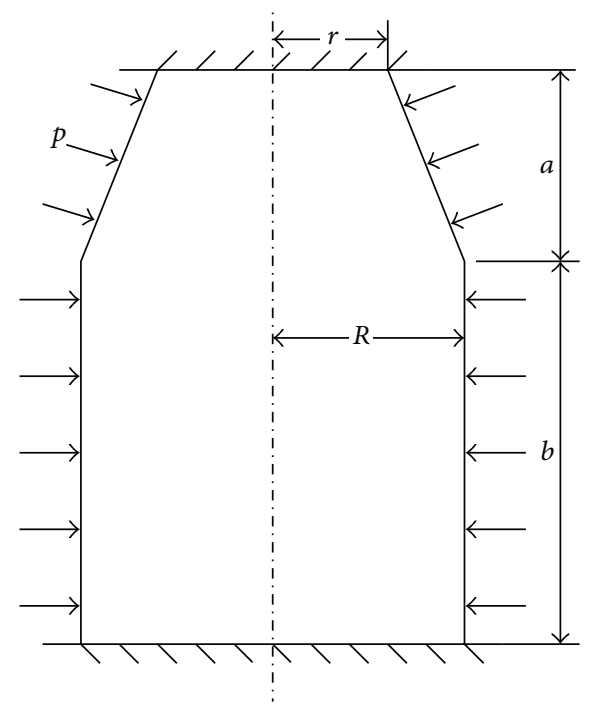

Figure 5: Dimensions of cone-cylinder structure.

the structure are fixed, with outer surfaces under a pressure of $p=0.3 \mathrm{Mpa}$. The material is shown in Table 1 , and the $0^{\circ}$ fiber direction is along the longitudinal direction of the cone and cylinder. The objective is to minimize the weight of the whole structure. The constraints are $f_{1} \geq 1700 \mathrm{~Hz}$ and $\lambda_{1} \geq 6$, where $f_{1}$ is the first-order frequency of the structure and $\lambda_{1}$ is the critical buckling factor, respectively.

The ground laminates were given as $\left[(0 / 45 /-45)_{10}\right] \mathrm{s}$ for the conic part and $\left[(0 / 45 /-45 / 90)_{7} / 0 / 45\right]$ s for the cylindrical part. Due to the restrictions on the manufacturing process in which the thickness of one layer could not be lower than $t$, the lower and upper bounds on ply thickness were set as $x_{i}^{L}=t$ and $x_{i}^{U}=4 t$, and the thickness of a removed ply was $x_{i}^{b}=0.01 t$. In addition, DPID $=0.95$ and FITP $=$ 0.8 . The best designs are known with 6 plies for the conic part and 8 plies for the cylindrical part, both referring to half of the laminates. The practical optima for this problem are designed as the feasible designs within $2.5 t$-ply weights of the cylindrical part for half of both laminates of the global optimum. Some stacking sequences of the practical optima obtained with the proposed strategy are shown in Table 2, with ply thicknesses not rounded. As for the rounded results, they are not discussed in this section when making comparisons between methods.

The performance of the original method (GATLA) and GATLA method with the improvements described previously (IGATLA) was compared based on different population sizes and maximum generation numbers. With 200 runs for each case, the optimization results are shown in Table 3 , and, in the GATLA method, the standard GA was used with $P_{c}=0.95$ and $P_{m}=0.05, R=0.1$. From the results in Table 3 , it could be seen that the computation costs could be significantly reduced, and the reliability is increased to a high level of around $90 \%$. For example, in the population size of 20 and maximum generations of 60 , the normalized computation price is reduced about $75.4 \%$ while the reliability is increased by $21 \%$. 
TABLE 1: Material properties.

\begin{tabular}{|c|c|c|c|c|c|}
\hline \multirow{2}{*}{ Property } & \multicolumn{5}{|c|}{ Value } \\
\hline & Example 1 & Example 2 & Example 3 & Example 4 & Example 5 \\
\hline Young's modulus, $E_{1}$ & $128 \mathrm{Gpa}$ & $138 \mathrm{Gpa}$ & $127.59 \mathrm{Gpa}$ & $135 \mathrm{Gpa}$ & $160 \mathrm{Gpa}$ \\
\hline Young's modulus, $E_{2}$ & $13 \mathrm{Gpa}$ & $11 \mathrm{Gpa}$ & $13.03 \mathrm{Gpa}$ & $9.12 \mathrm{Gpa}$ & $9.0 \mathrm{Gpa}$ \\
\hline Shear modulus, $G_{12}$ & $6.4 \mathrm{Gpa}$ & $6.5 \mathrm{Gpa}$ & $6.41 \mathrm{Gpa}$ & $5.67 \mathrm{Gpa}$ & $4.8 \mathrm{Gpa}$ \\
\hline Poisson's ratio, $v_{12}$ & 0.3 & 0.28 & 0.3 & 0.31 & 0.36 \\
\hline Ply thickness, $t$ & $0.127 \mathrm{~mm}$ & $0.125 \mathrm{~mm}$ & $0.127 \mathrm{~mm}$ & $0.12 \mathrm{~mm}$ & $0.08 \mathrm{~mm}$ \\
\hline Density, $\rho$ & $1600 \mathrm{~kg} / \mathrm{m}^{3}$ & $1600 \mathrm{~kg} / \mathrm{m}^{3}$ & $1577.8 \mathrm{~kg} / \mathrm{m}^{3}$ & $1600 \mathrm{~kg} / \mathrm{m}^{3}$ & $1600 \mathrm{~kg} / \mathrm{m}^{3}$ \\
\hline
\end{tabular}

TABLE 2: Practical optima of cone-cylinder structure.

\begin{tabular}{|c|c|c|c|c|}
\hline $\begin{array}{l}\text { Laminate } \\
\text { Co: conic part } \\
\text { Cy: cylindrical part }\end{array}$ & Plies & Weight, kg & $f_{1}, \mathrm{~Hz}$ & $\lambda_{b}$ \\
\hline $\begin{array}{l}\left.-45_{2} / 0 / 45 / 0 / 45\right] \mathrm{s} \\
{\left[-45 / 90 / 0 / 45 /-45 / 45 / 0_{2}\right] \mathrm{s}}\end{array}$ & $\begin{array}{l}\mathrm{Co})-[12] \\
(\mathrm{Cy})-[16]\end{array}$ & 0.5622 & 1713.0 & 6.0637 \\
\hline $\begin{array}{l}{\left[0 / 45 / 0 / 45 /-45_{2} / 0\right] \mathrm{s}} \\
{\left[90_{2} /-45 / 0 / 45 /-45 / 45 / 0\right] \mathrm{s}} \\
\end{array}$ & $\begin{array}{l}(\mathrm{Co})-[14] \\
(\mathrm{Cy})-[16] \\
\end{array}$ & 0.5623 & 1735.4 & 6.5342 \\
\hline $\begin{array}{l}{\left[45_{2} / 0 /-45 / 45_{2} /-45\right] \mathrm{s}} \\
{[90 /-45 / 90 / 0 / 45 / 0 /-45 / 0] \mathrm{s}}\end{array}$ & $\begin{array}{l}(\mathrm{Co})-[14] \\
(\mathrm{Cy})-[16]\end{array}$ & 0.5623 & 1702.2 & 6.9326 \\
\hline $\begin{array}{l}{\left[45_{2} / 0 / 45 / 0 /-45 / 45\right] \mathrm{s}} \\
{[90 / 45 /-45 / 0 / 45 /-45 / 45 / 0] \mathrm{s}}\end{array}$ & $\begin{array}{l}(\mathrm{Co})-[14] \\
(\mathrm{Cy})-[16]\end{array}$ & 0.5723 & 1738.1 & 6.9188 \\
\hline $\begin{array}{l}{\left[45_{2} /-45_{2} / 0 / 45\right] \mathrm{s}} \\
{\left[90 / 45 / 0 /-45_{2} / 0 / 45 / 0\right] \mathrm{s}}\end{array}$ & $\begin{array}{l}(\mathrm{Co})-[12] \\
(\mathrm{Cy})-[16]\end{array}$ & 0.5403 & 1709.2 & 5.9711 \\
\hline $\begin{array}{l}{\left[45 /-45_{2} / 45 /-45 / 0\right] \mathrm{s}} \\
{\left[-45 / 45 /-45 / 90 / 45 / 90 / 0_{2} / 45\right] \mathrm{s}}\end{array}$ & $\begin{array}{l}(\mathrm{Co})-[12] \\
(\mathrm{Cy})-[18]\end{array}$ & 0.5914 & 1715.1 & 6.2208 \\
\hline $\begin{array}{l}{\left[-45 / 0_{2} /-45 / 0 /-45 / 0\right] \mathrm{s}} \\
{\left[0 /-45 / 90 / 45 / 90 / 45 /-45_{2} / 0\right] \mathrm{s}}\end{array}$ & $\begin{array}{l}\text { (Co) }-[14] \\
(\mathrm{Cy})-[18] \\
\end{array}$ & 0.6134 & 1710.1 & 6.8836 \\
\hline $\begin{array}{l}{\left[0 / 45 /-45 / 0 /-45 / 0 /-45_{2}\right] \mathrm{s}} \\
{[90 / 45 /-45 / 0 /-45 / 0 / 45 / 0] \mathrm{s}}\end{array}$ & $\begin{array}{l}(\mathrm{Co})-[16] \\
(\mathrm{Cy})-[16]\end{array}$ & 0.5843 & 1742.9 & 6.5043 \\
\hline
\end{tabular}

4.2. A Two-Patch Panel. The second example for a twopatch panel stacking sequence optimization [26] is selected to further demonstrate the efficiency of IGATLA method, with minimum weight as objective and critical buckling factor not less than 0.76 as constraint under the loading $N_{x}=$ $25 \mathrm{~N} / \mathrm{mm}$. This structure consists of three laminates, two identical laminates along the edges, shown in Figure 6. The plate is simply supported on its edges and all four external edges remain straight. The composite material properties are also shown in Table 1. The best designs have been known with 24 plies for the exterior laminate and 8 plies for the interior part. The practical optima here are defined as the feasible designs within $2 t$-ply weights for one half of the exterior/interior laminate of the global optimum. 200 independent optimization runs are performed to show the computational performance.

Starting with $\left[(0 / 45 /-45)_{5}\right] \mathrm{s}$ and $\left[(-45 / 45 / 90)_{2}\right] \mathrm{s}$ as the ground laminates for the exterior and interior part, respectively, the optimization is conducted with 200 repeated runs, where the population size and maximum generation number are both 100; DPID $=0.28$ and FITP $=0.96$. Table 4 lists several practical optima obtained with GATLA method.

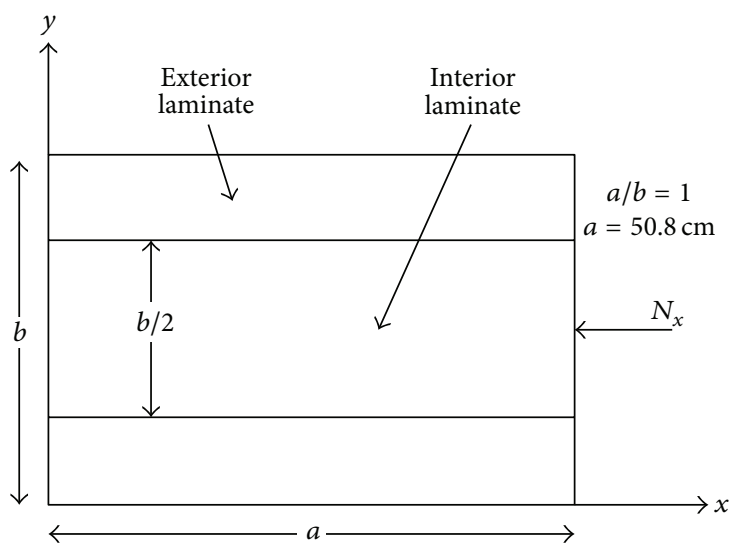

FIGURE 6: Geometry and loading of the considered two-patch panels.

It shows that this strategy is effective in dealing with stacking sequence optimization and more near optimal designs can be provided for the designer. Table 5 compares the efficiency 
TABLE 3: Computational performance comparison.

\begin{tabular}{|c|c|c|c|c|c|}
\hline \multirow{2}{*}{ Population size } & \multirow{2}{*}{ Maximum generation number } & \multicolumn{2}{|c|}{ Normalized computation price } & \multicolumn{2}{|c|}{ Reliability } \\
\hline & & GATLA & IGATLA & GATLA & IGATLA \\
\hline 20 & 60 & 36.05 & 8.89 & 0.69 & 0.90 \\
\hline 80 & 60 & 21.96 & 11.18 & 0.80 & 0.87 \\
\hline 120 & 60 & 24.61 & 11.84 & 0.79 & 0.85 \\
\hline 120 & 100 & 20.87 & 10.64 & 0.92 & 0.89 \\
\hline
\end{tabular}

TABle 4: Practical optima of composite panels.

\begin{tabular}{|c|c|c|c|c|}
\hline & $\begin{array}{l}\text { Laminate } \\
\text { Ex: exterior part } \\
\text { In: interior part }\end{array}$ & Plies & Weight, kg (B/A) & Critical buckling factor (B/A) \\
\hline Case 1 & $\begin{array}{l}{\left[0 / 45 /-45 / 0 /-45 / 45 / 0 / 45 /-45 / 0 /-45_{2}\right] \mathrm{s}} \\
{\left[90 / 45 / 90_{2}\right] \mathrm{s}}\end{array}$ & $\begin{array}{l}(\mathrm{Ex})-[24] \\
(\mathrm{In})-[08]\end{array}$ & $0.8258 / 0.8258$ & $0.76 / 0 / 76$ \\
\hline Case 2 & $\begin{array}{l}{[0 / 45 / 0 / 45 /-45 / 0 /-45 / 0 /-45 / 0 /-45 / 45] \mathrm{s}} \\
{[-45 / 90 /-45 / 90] \mathrm{s}}\end{array}$ & $\begin{array}{l}(\mathrm{Ex})-[24] \\
(\mathrm{In})-[08]\end{array}$ & $0.8343 / 0.8258$ & $0.73 / 0.72$ \\
\hline Case 3 & $\begin{array}{l}{\left[0_{2} / 45 /-45 / 0 / 45 /-45 / 0_{2} / 45 /-45 / 0\right] \mathrm{s}} \\
{[90 / 45 /-45 / 90] \mathrm{s}}\end{array}$ & $\begin{array}{l}(\mathrm{Ex})-[24] \\
(\mathrm{In})-[08]\end{array}$ & $0.8258 / 0.8258$ & $0.74 / 0.74$ \\
\hline Case 4 & $\begin{array}{l}{\left[0 / 45 /-45 / 0 / 45 /-45 / 0_{2} / 45 /-45 / 0 / 45\right] \mathrm{s}} \\
{[-45 / 90 /-45 / 45 / 90] \mathrm{s}}\end{array}$ & $\begin{array}{l}(\mathrm{Ex})-[24] \\
(\mathrm{In})-[10]\end{array}$ & $0.8774 / 0.8774$ & $0.77 / 0.77$ \\
\hline Case 5 & $\begin{array}{l}{[0 /-45 / 0 / 45 /-45 / 0 / 45 /-45 / 0 /-45 / 0 /-45] \mathrm{s}} \\
{[-45 / 45 / 90 /-45 / 90] \mathrm{s}}\end{array}$ & $\begin{array}{l}(\mathrm{Ex})-[24] \\
(\mathrm{In})-[10]\end{array}$ & $0.8774 / 0.8774$ & $0.78 / 0.78$ \\
\hline Reference [26] & $\begin{array}{l}{\left[(-45 / 45)_{2} / 45 / 0 /-45 / 0_{5}\right] \mathrm{s}} \\
{[90 /-45 / 45 / 90] \mathrm{s}}\end{array}$ & $\begin{array}{l}(\mathrm{Ex})-[24] \\
(\mathrm{In})-[08]\end{array}$ & 0.8258 & $0.81^{\#} / 0.76^{\# \#}$ \\
\hline
\end{tabular}

A: after rounding, B: before rounding; \#: critical buckling factor in reference, and \#\#: value given by Nastran.

TABLE 5: Computational performance comparison.

\begin{tabular}{lcc}
\hline Methods & Normalized computation price & Reliability \\
\hline GATLA & 17.80 & 0.97 \\
IGATLA & 8.56 & 1.00 \\
Reference [26] & 25 & \\
\hline
\end{tabular}

of the GATLA and IGATLA methods, as well as the number of finite element analysis in [26]. It can be seen that whether with improvements or not the GATLA approach exhibits lower computational costs, and by directly dealing with stacking sequences and thicknesses of each ply no intermediate variables like lamination parameters in [26] are used. Additionally, with the improvements in the GATLA method, the normalized computational cost is reduced from 17.80 to 8.56 . So the computational cost saves $51.9 \%$ with these improvements. It could be concluded that noticeable improvements in the computational cost are obtained, and meanwhile a higher level of feasibility is achieved.

\section{Engineering Applications}

5.1. A Missile Rudder Structure Component Design. The first industrial application is to design the stacking sequence of a structural component from the missile rudder, which is to show the applicability of optimizing practical structures. The simplified geometry model and its dimensions are shown in Figure 7, and the length units are all millimeter, that is, $\mathrm{mm}$. The semicircle region with a radius of $21.6 \mathrm{~mm}$ at the bottom is fixed, and a uniform distributed force with the total value of $5000 \mathrm{~N}$ is applied along the red line, $72 \mathrm{~mm}$ away from the bottom edge. The applied force is perpendicular to the surface of the composite plate. The properties of the composite materials are also shown in Table 1 , and the 0 degree fibre direction is along the $y$ direction. The objective is to minimize the weight of the composite plate. The constraint is that the maximum displacement of the whole structure should not be more than $3 \mathrm{~mm}$.

The optimization parameters are $x_{i}^{L}=t, x_{i}^{U}=4 t$, $x_{i}^{b}=0.01 t$, DPID $=0.95$, and FITP $=0.9$. Three optimization cases are studied based on three different ground laminates: $\left[(0 / \pm 45 / 90)_{25}\right] \mathrm{s}$ (Case 1$),\left[( \pm 45 / 0 / 90)_{25}\right] \mathrm{s}$ (Case $2)$, and $\left[(0 / \pm 45 / 90)_{20}\right] \mathrm{s}$ (Case 3$)$. In Case 1 , there are 100 continuous thickness variables and 100 discrete variables. For Case 2, the number of design variables is equal to that of Case 1. The difference between them is the sequences in the ground laminates. Compared with Cases 1 and 2, fewer variables are involved in Case 3, that is, 80 thickness variables and 80 discrete variables. Considering the balanced constraint, the thickness variables of adjacent $+45^{\circ}$ and $-45^{\circ}$ plies are linked together in all three cases. The population size $N$ and generation number $\operatorname{Max} G$ are 100 and 150, respectively. The optimization results obtained from the three cases are summarized in Table 6, where the thicknessrounded design results and not rounded designs are the same. 


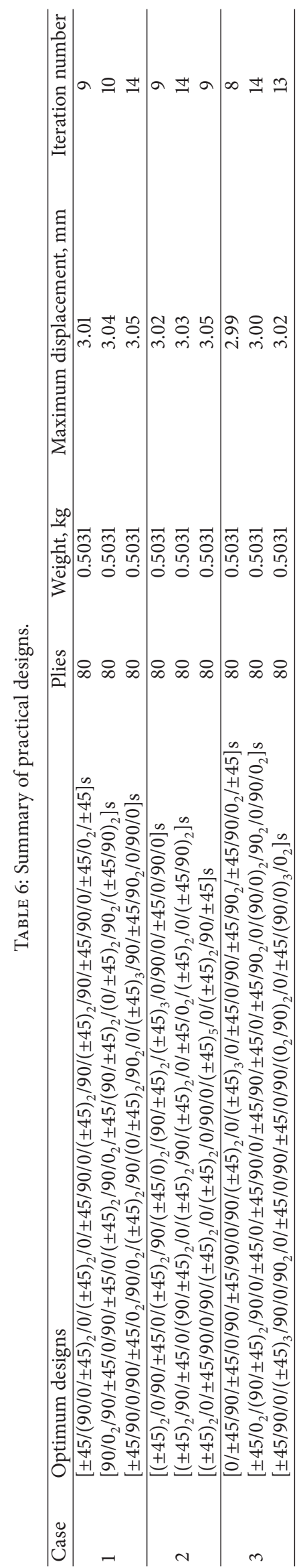




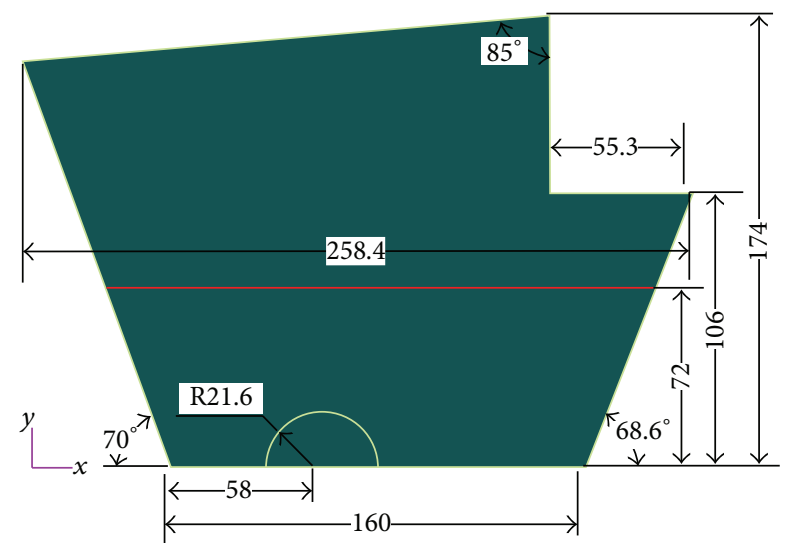

FIGURE 7: Geometry model and its dimensions of a missile rudder structure component.

TABLE 7: Load cases.

\begin{tabular}{lcc}
\hline \multirow{2}{*}{ Load case } & \multicolumn{2}{c}{ Overloading, g } \\
& Transverse & Longitudinal \\
\hline 1 & 1.80 & -5.40 \\
2 & 1.65 & -8.85 \\
3 & 1.65 & -5.85 \\
4 & 1.35 & -10.50 \\
\hline
\end{tabular}

With certain errors allowed, these results are acceptable, providing alternatives for the designer. Moreover, it can be seen that the proposed method is also effective starting with different ground laminates, which shows its robustness and applicability in dealing with practical structures.

5.2. A Satellite Structure Design. To further verify the practicality of the developed optimization system in engineering applications, the stacking sequences of the main cylinder in a satellite are optimized to provide the designer with a choice of alternatives. All of the calculations are conducted in a computer with CPU $3.30 \mathrm{GHz} / \mathrm{RAM} 8.00 \mathrm{G}$.

A satellite structure is composed of two parts: the main structure platform and the payload cabin. It is connected with the launch vehicle through a joint ring in the bottom of the main structure platform. In the main structure platform, a main cylinder with a conic part and a cylindrical part is designed, the stacking sequence of which needs to be optimized. The stiffness of the whole satellite should satisfy the requirement that the first-order natural transverse frequency, $f_{1}$, is not lower than $15 \mathrm{~Hz}$. Meanwhile, the design should also meet the stability demand that under each launch condition load, listed in Table 7, the critical buckling factor should not be less than 1.5.

Based on the primal design of the satellite structure, an FE (finite element) model was established with Patran, and the FE model of the main structure platform is shown in Figure 8, with a side panel and payload cabin removed. The main cylinder is also shown in Figure 8. Based on the connecting interface between the satellite and launch vehicle, the boundary condition is to fix the bottom of the joint ring.

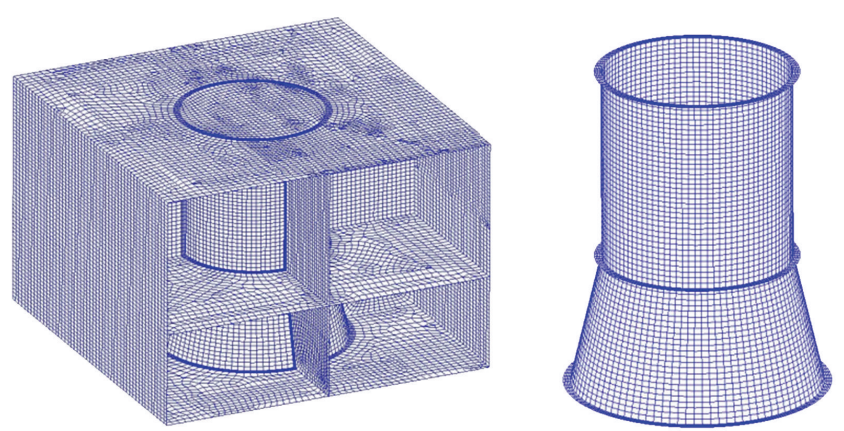

FIGURE 8: FE model of main structure platform in satellite structure.

In the optimization calculation, the ground laminate was given as $\left[(0 / \pm 45 / 90)_{5}\right]$ s for the cylindrical part, with $\left[(0 / \pm 45)_{6}\right] \mathrm{s}$ for the conic part. And $0^{\circ}$ fiber direction is along the longitudinal direction of the main cylinder. For the composite material properties in the design space, they are listed in Table 1. Considering the balanced constraint requirement that the number of $+45^{\circ}$ plies should be equal to the number of $-45^{\circ}$ plies, the thickness variables of adjacent $+45^{\circ}$ and $-45^{\circ}$ plies are enforced to link together here. The population size and maximum generation number in GA are 80 and 60 , respectively. Among the constraints, the firstorder natural transverse frequency, $f_{1}$, and critical buckling factor under Load Case $4, \lambda_{b, 4}$, are set as constraint functions which will be satisfied automatically during the optimum calculation. Critical buckling factors under the other three load cases act as measurements to verify the optimized structure. The objective is to seek the minimum weight. Table 8 shows several optimization results of the stacking sequences with ply thicknesses not rounded. As the deleted piles with $0.01 t$-thickness are removed completely here for structural analyses in Table 8, a few critical buckling factors are a bit less than 1.5 .

According to the results shown in Table 8, the stacking sequences are redesigned next by rounding the thicknesses and adding one or more plies if needed to meet the design requirements. The redesigned results are presented in Table 9, and it can be found that the stiffness and the stability of the final solutions basically satisfy all the design constraints, which provided guidelines to the detailed design of the satellite structure. Besides, as could be seen in Table 8, less than twenty-five structural analyses were implemented during the whole process for these five result cases, which means that this optimization strategy can supply reasonable solutions efficiently even for large-scale engineering problem.

\section{Conclusions}

By considering practical engineering requirements, the genetic algorithm using a two-level approximation devised in previous work for stacking sequence optimization was improved in the present study, and the performance was investigated with more typical numerical examples and industrial applications. With these improved optimization 
TABLE 8: Summary of stacking sequence designs.

\begin{tabular}{|c|c|c|c|c|c|c|c|}
\hline & $\begin{array}{l}\text { Laminate } \\
\text { Co: conic part } \\
\text { Cy: cylindrical part }\end{array}$ & Plies & $\begin{array}{l}\text { Weight of main } \\
\text { cylinder, kg }\end{array}$ & $f_{1}, \mathrm{~Hz}$ & $\lambda_{b, 4}$ & $\begin{array}{c}\text { Number of } \\
\text { structural analyses }\end{array}$ & CPU cost, h \\
\hline Case 1 & $\begin{array}{l}{\left[45 /-45 / 90_{2}\right] \mathrm{s}} \\
{[45 /-45 / 0 / 45 /-45 / 0] \mathrm{s}}\end{array}$ & $\begin{array}{l}(\mathrm{Cy})-[08] \\
(\mathrm{Co})-[12] \\
\end{array}$ & 3.068 & 17.335 & 1.4425 & 6 & 1.15 \\
\hline Case 2 & $\begin{array}{l}{\left[90_{2} / 45 /-45\right] \mathrm{s}} \\
{\left[0 / 45_{3} /-45_{3} / 0_{2}\right] \mathrm{s}}\end{array}$ & $\begin{array}{l}(\mathrm{Cy})-[08] \\
(\mathrm{Co})-[18] \\
\end{array}$ & 3.254 & 17.423 & 1.4664 & 15 & 2.95 \\
\hline Case 3 & $\begin{array}{l}{\left[90 / 45_{2} /-45_{2}\right] \mathrm{s}} \\
{\left[0 / 45_{2} /-45_{2} / 0_{2}\right] \mathrm{s}}\end{array}$ & $\begin{array}{l}(\mathrm{Cy})-[10] \\
(\mathrm{Co})-[14]\end{array}$ & 3.096 & 17.625 & 1.5598 & 23 & 4.51 \\
\hline Case 4 & $\begin{array}{l}{\left[45 /-45 / 90_{2}\right] \mathrm{s}} \\
{[0 / 45 /-45 / 0 / 45 /-45] \mathrm{s}}\end{array}$ & $\begin{array}{l}(\mathrm{Cy})-[08] \\
(\mathrm{Co})-[12] \\
\end{array}$ & 3.250 & 17.335 & 1.6774 & 20 & 4.01 \\
\hline Case 5 & $\begin{array}{l}{\left[45 /-45 / 90_{2}\right] \mathrm{s}} \\
{\left[45_{3} /-45_{3} / 0_{2}\right] \mathrm{s}}\end{array}$ & $\begin{array}{l}(\mathrm{Cy})-[08] \\
(\mathrm{Co})-[16]\end{array}$ & 3.279 & 17.544 & 1.4190 & 11 & 2.18 \\
\hline
\end{tabular}

TABLE 9: Redesigned stacking sequence results.

\begin{tabular}{|c|c|c|c|c|c|c|c|c|}
\hline & \multirow{2}{*}{$\begin{array}{l}\text { Laminate } \\
\text { Co: conic part } \\
\text { Cy: cylindrical part }\end{array}$} & \multirow[b]{2}{*}{ Plies } & \multirow[b]{2}{*}{$\begin{array}{l}\text { Weight of main } \\
\text { cylinder, kg }\end{array}$} & \multirow[b]{2}{*}{$f_{1}, \mathrm{~Hz}$} & \multicolumn{4}{|c|}{ Critical buckling factors } \\
\hline & & & & & $\lambda_{b, 1}$ & $\lambda_{b, 2}$ & $\lambda_{b, 3}$ & $\lambda_{b, 4}$ \\
\hline Case 1 & $\begin{array}{l}{\left[45 /-45 / 90_{2} / \overline{0}\right] \mathrm{s}} \\
{\left[45 /-45 / 0_{2} / 45 /-45 / 0\right] \mathrm{s}}\end{array}$ & $\begin{array}{l}(\mathrm{Cy})-[09] \\
(\mathrm{Co})-[14]\end{array}$ & 3.110 & 17.361 & 1.9392 & 1.5705 & 1.9589 & 1.5188 \\
\hline Case 2 & $\begin{array}{l}{\left[90_{2} / 45 /-45\right] \mathrm{s}} \\
{\left[0 / 45_{3} /-45_{3} / 0_{2}\right] \mathrm{s}}\end{array}$ & $\begin{array}{l}(\mathrm{Cy})-[08] \\
(\mathrm{Co})-[18] \\
\end{array}$ & 3.434 & 17.576 & 1.9129 & 1.5794 & 1.9457 & 1.4702 \\
\hline Case 3 & $\begin{array}{l}{\left[90 / 45_{2} /-45_{2}\right] \mathrm{s}} \\
{\left[0 / 45_{2} /-45_{2} / 0_{2}\right] \mathrm{s}}\end{array}$ & $\begin{array}{l}(\mathrm{Cy})-[10] \\
(\mathrm{Co})-[14] \\
\end{array}$ & 3.268 & 17.903 & 1.8887 & 1.6462 & 1.9672 & 1.5914 \\
\hline Case 4 & $\begin{array}{l}{\left[45 /-45 / 90_{2} / \overline{0}\right] \mathrm{s}} \\
{[0 / 45 /-45 / 0 / 45 /-45 / 0] \mathrm{s}}\end{array}$ & $\begin{array}{l}(\mathrm{Cy})-[09] \\
(\mathrm{Co})-[14] \\
\end{array}$ & 3.110 & 17.361 & 1.9081 & 1.7142 & 1.9920 & 1.6837 \\
\hline Case 5 & $\begin{array}{l}{\left[45 /-45 / 90_{2} / \overline{0}\right] \mathrm{s}} \\
{\left[45_{3} /-45_{3} / 0_{2}\right] \mathrm{s}}\end{array}$ & $\begin{array}{l}(\mathrm{Cy})-[09] \\
(\mathrm{Co})-[16]\end{array}$ & 3.351 & 17.417 & 2.0974 & 1.7528 & 2.1539 & 1.6881 \\
\hline
\end{tabular}

strategies including improved random initial design, adaptive penalty fitness function, adaptive crossover probability, and variable mutation probability, as well as enhanced validity check criterion for multiple laminates, significantly higher computational efficiency and reliability than before have been obtained, which also relieve the designers from the burden of determining several control parameters. Meanwhile, a wealth of near optimal designs could be produced easily as well. By applying this strategy in practical engineering problems, it has been found that reasonable stacking sequences have been obtained, and this method is capable of conducting practical engineering optimizations efficiently to provide the designer with a choice of alternatives.

\section{Conflict of Interests}

The authors declare that there is no conflict of interests regarding the publication of this paper.

\section{Acknowledgment}

The authors acknowledge the support of this research work received from the National Natural Science Foundation of China (Grant no. 11102009).

\section{References}

[1] H. Fukunaga and H. Sekine, "Stiffness design method of symmetric laminates using lamination parameters," AIAA Journal, vol. 30, no. 11, pp. 2791-2793, 1992.

[2] R. Le Riche and R. T. Haftka, "Optimization of laminate stacking sequence for buckling load maximization by genetic algorithm," AIAA journal, vol. 31, no. 5, pp. 951-956, 1993.

[3] R. le Riche and R. T. Haftka, "Improved genetic algorithm for minimum thickness composite laminate design," Composites Engineering, vol. 5, no. 2, pp. 143-161, 1995.

[4] B. Liu, R. T. Haftka, M. A. Akgün, and A. Todoroki, "Permutation genetic algorithm for stacking sequence design of composite laminates," Computer Methods in Applied Mechanics and Engineering, vol. 186, no. 2-4, pp. 357-372, 2000.

[5] A. Todoroki and M. Sekishiro, "New iteration fractal branch and bound method for stacking sequence optimizations of multiple laminates," Composite Structures, vol. 81, no. 3, pp. 419-426, 2007.

[6] J. H. Park, J. H. Hwang, C. S. Lee, and W. Hwang, "Stacking sequence design of composite laminates for maximum strength using genetic algorithms," Composite Structures, vol. 52, no. 2, pp. 217-231, 2001.

[7] M. Cho and S. Y. Rhee, "Layup optimization considering freeedge strength and bounded uncertainty of material properties," AIAA Journal, vol. 41, no. 11, pp. 2274-2282, 2003. 
[8] M. Shakeri, M. H. Yas, and M. Ghasemi Gol, "Optimal stacking sequence of laminated cylindrical shells using genetic algorithm," Mechanics of Advanced Materials and Structures, vol. 12, no. 4, pp. 305-312, 2005.

[9] S. Nagendra, D. Jestin, Z. Gürdal, R. T. Haftka, and L. T. Watson, "Improved genetic algorithm for the design of stiffened composite panels," Computers and Structures, vol. 58, no. 3, pp. 543-555, 1996.

[10] G. Soremekun, Z. Gürdal, R. T. Haftka, and L. T. Watson, "Improving genetic algorithm efficiency and reliability in the design and optimization of composite structures," Tech. Rep. TR-96-13, Department of Computer Science, Virginia Polytechnic Institute and State University, Blacksburg, Va, USA, 1996.

[11] B. Liu, R. T. Haftka, and M. A. Akgün, "Composite wing structural optimization using genetic algorithms and response surfaces," in Proceedings of the 7th AIAA/USAF/NASA/ISSMO Symposium on Multidisciplinary Analysis and Optimization, pp. 1-12, St. Louis, Mo, USA, 1998.

[12] V. B. Gantovnik, Z. Gürdal, and L. T. Watson, "A genetic algorithm with memory for optimal design of laminated sandwich composite panels," Composite Structures, vol. 58, no. 4, pp. 513520, 2002.

[13] A. Todoroki and T. Ishikawa, "Design of experiments for stacking sequence optimizations with genetic algorithm using response surface approximation," Composite Structures, vol. 64, no. 3-4, pp. 349-357, 2004.

[14] P. Kere and J. Lento, "Design optimization of laminated composite structures using distributed grid resources," Composite Structures, vol. 71, no. 3-4, pp. 435-438, 2005.

[15] C. H. Park, W. I. Lee, W. S. Han, and A. Vautrin, "Improved genetic algorithm for multidisciplinary optimization of composite laminates," Computers and Structures, vol. 86, no. 19-20, pp. 1894-1903, 2008.

[16] K. Yamazaki, "Two-level optimization technique of composite laminate panels by genetic algorithms," in Proceedings of the 37th AIAA/ASME/ASCE/AHS/ASC Structures, Structural Dynamics, and Materials Conference and Exhibit, pp. 1882-1887, AIAA, Salt Lake City, Utah, USA, 1996.

[17] H. Ghiasi, D. Pasini, and L. Lessard, "Optimum stacking sequence design of composite materials Part I: constant stiffness design," Composite Structures, vol. 90, no. 1, pp. 1-11, 2009.

[18] S. Chen, Z. Lin, H. An, H. Huang, and C. Kong, "Stacking sequence optimization with genetic algorithm using a two-level approximation," Structural and Multidisciplinary Optimization, vol. 48, no. 4, pp. 795-805, 2013.

[19] A. Todoroki and M. Sekishiro, "Stacking sequence optimization to maximize the buckling load of blade-stiffened panels with strength constraints using the iterative fractal branch and bound method," Composites Part B: Engineering, vol. 39, no. 5, pp. 842-850, 2008.

[20] M. Ohsaki, "Genetic algorithm for topology optimization of trusses," Computers \& Structures, vol. 57, no. 2, pp. 219-225, 1995.

[21] H. J. C. Barbosa and A. C. C. Lemonge, "A new adaptive penalty scheme for genetic algorithms," Information Sciences, vol. 156, no. 3-4, pp. 215-251, 2003.

[22] X. Liu, G. Cheng, J. Yan, and L. Jiang, "Singular optimum topology of skeletal structures with frequency constraints by AGGA," Structural and Multidisciplinary Optimization, vol. 45, no. 3, pp. 451-466, 2012.
[23] M. Srinivas and L. M. Patnaik, "Adaptive probabilities of crossover and mutation in genetic algorithms," IEEE Transactions on Systems, Man and Cybernetics, vol. 24, no. 4, pp. 656-667, 1994.

[24] Z.-W. Ren and Y. San, "Improved adaptive genetic algorithm and its application research in parameter identification," Journal of System Simulation, vol. 18, no. 1, pp. 41-43, 2006.

[25] J. P. B. Leite and B. H. V. Topping, "Improved genetic operators for structural engineering optimization," Advances in Engineering Software, vol. 29, no. 7-9, pp. 529-562, 1998.

[26] F.-X. Irisarri, M. M. Abdalla, and Z. Gürdal, "Improved shepard's method for the optimization of composite structures," AIAA Journal, vol. 49, no. 12, pp. 2726-2736, 2011. 


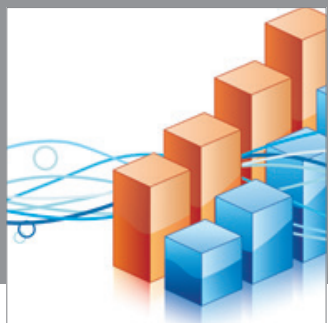

Advances in

Operations Research

mansans

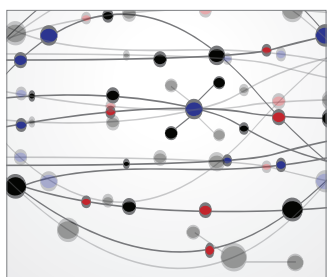

The Scientific World Journal
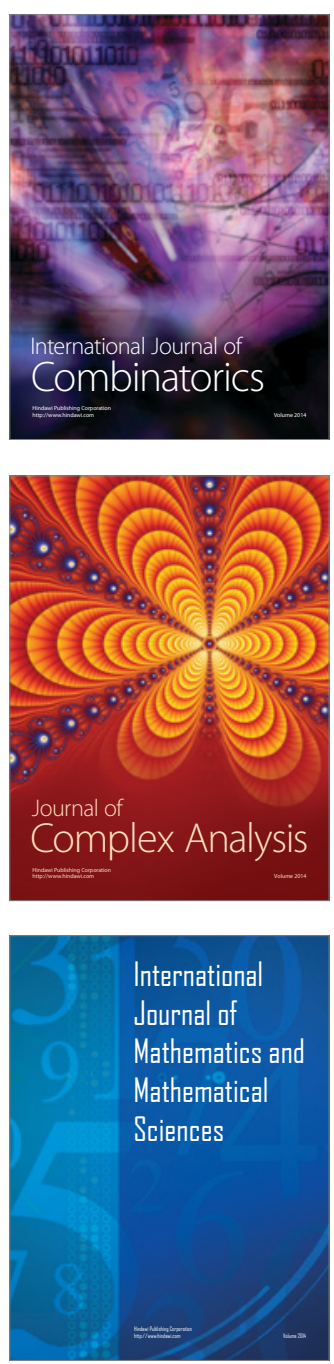
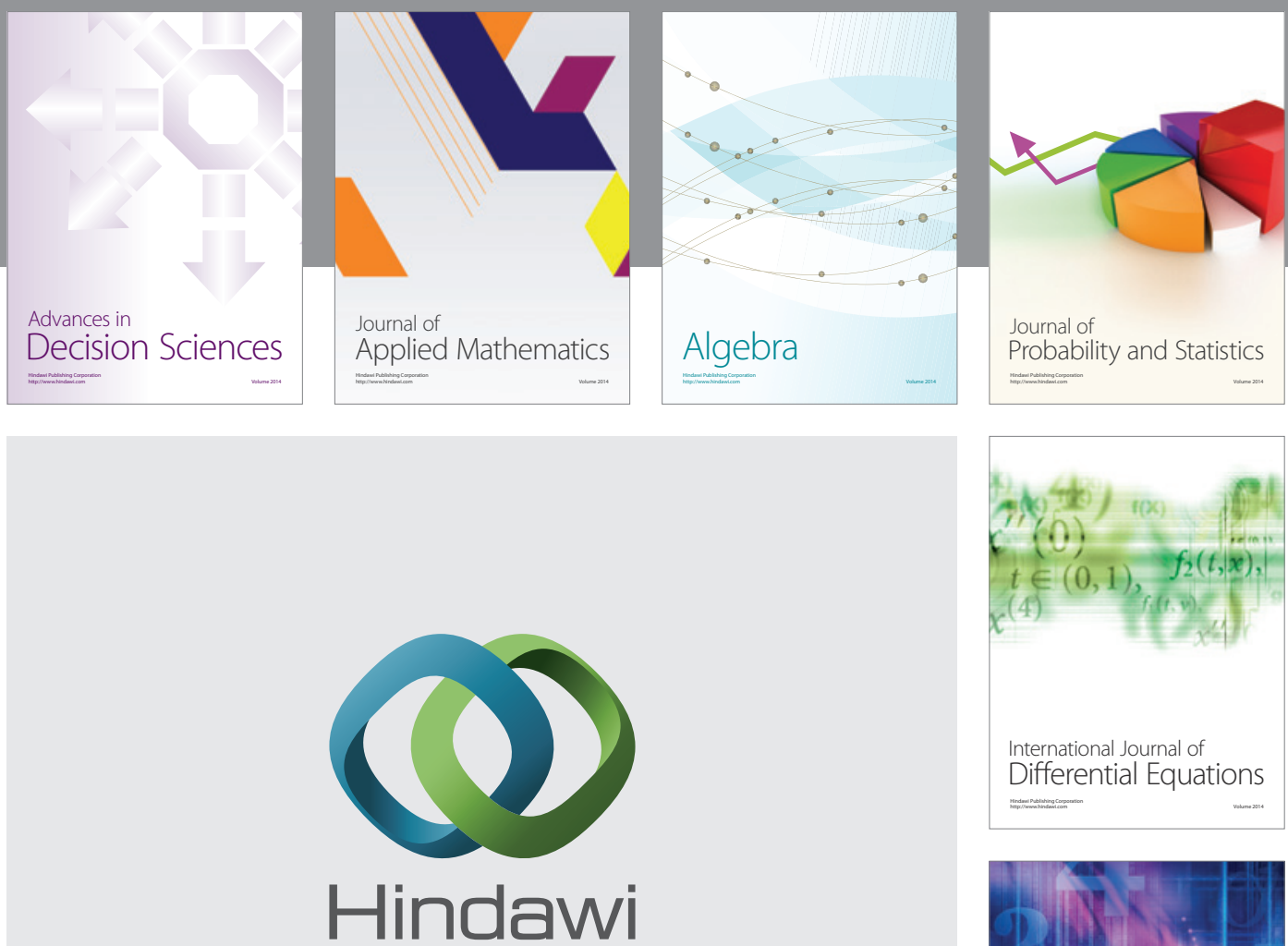

Submit your manuscripts at http://www.hindawi.com
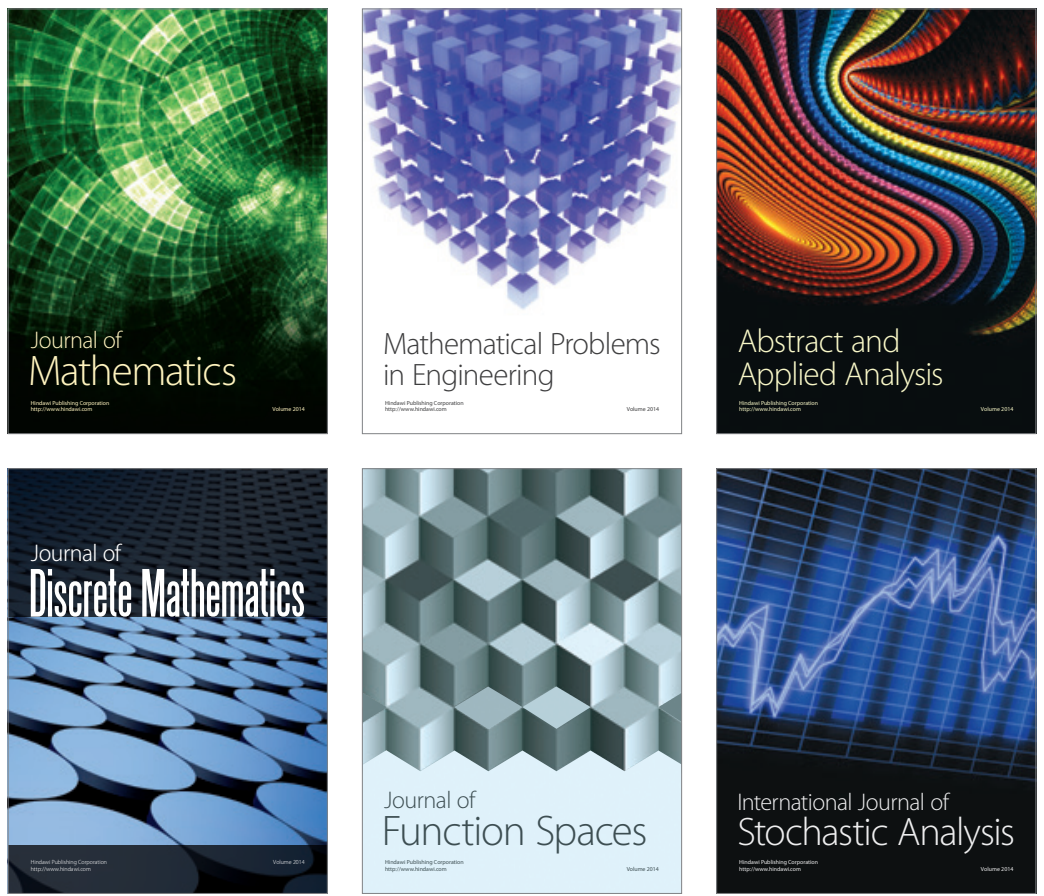

Journal of

Function Spaces

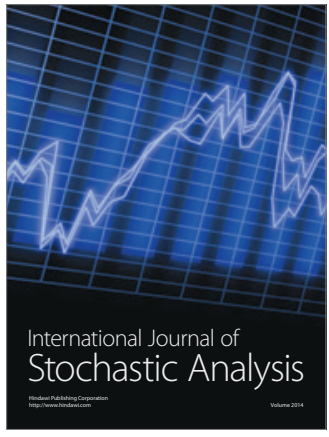

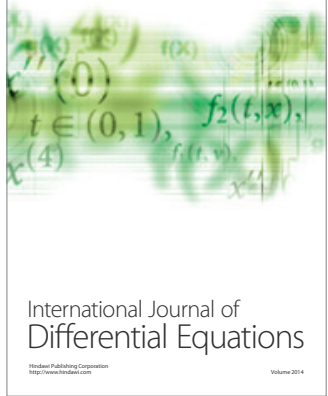
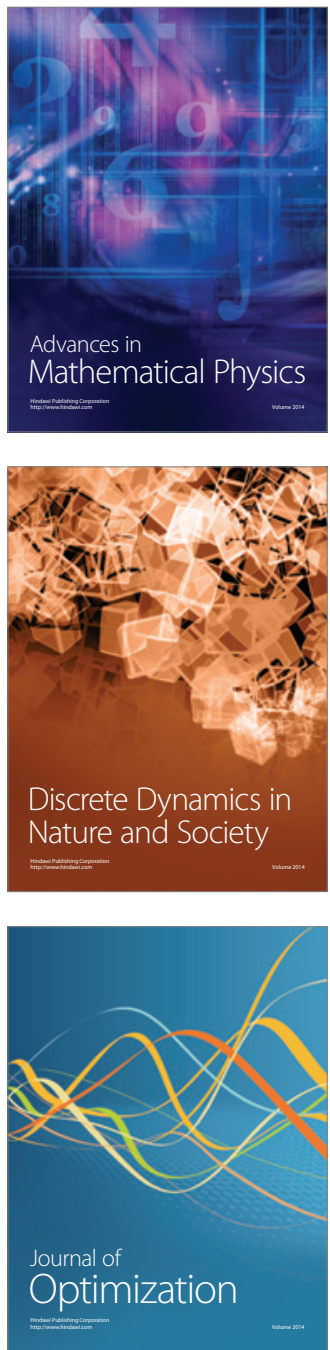